\title{
ALCANCES DE LA LOEI DE LA REPÚBLICA DEL ECUADOR (2011) EN MATERIA DE NECESIDADES EDUCATIVAS ESPECIALES: UN ESTUDIO DE CASO ASOCIADO A DISCAPACIDAD VISUAL
}

\section{SCOPES OF LOEI OF THE REPUBLIC OF ECUADOR (2011) IN THE MATTER OF SPECIAL EDUCATION NEEDS: A CASE STUDY ASSOCIATED TO VISUAL DISABILITY.}

\author{
VERÓNICA MALDONADO GARCÉS ${ }^{1}$ \\ ELKING RAYMOND ARAUJO ${ }^{2}$
}

Recibido: 15 de mayo de 2017

Aceptado: 29 de agosto de 2017

\footnotetext{
${ }^{1}$ Pontificia Universidad Católica del Ecuador, Facultad de Psicología, Quito, Ecuador (vmaldonado794@puce.edu.ec).

${ }^{2}$ Pontificia Universidad Católica del Ecuador, Facultad de Psicología, Quito, Ecuador (eraraujo@puce.edu.ec).
} 



\section{ALCANCES DE LA LOEI DE LA REPÚBLICA DEL ECUADOR (2011) EN MATERIA DE NECESIDADES EDUCATIVAS ESPECIALES: UN ESTUDIO DE CASO ASOCIADO A DISCAPACIDAD VISUAL}

\section{SCOPES OF LOEI OF THE REPUBLIC OF ECUADOR (2011) IN THE MATTER OF SPECIAL EDUCATION NEEDS: A CASE STUDY ASSOCIATED TO VISUAL DISABILITY}

Verónica Maldonado Garcés, Elking Raymond Araujo

Palabras clave: inclusión educativa, discapacidad visual, TICS, LOEI Key words: educational inclusion, visual disability TICS, LOEl

\section{RESUMEN}

La aprobación de la Constitución de la República del Ecuador (2008) y la promulgación de la Ley Orgánica de Educación Intercultural (2011) marcaron un hito en el tratamiento de las Necesidades Educativas Especiales en el Ecuador (NEE). Es innegable que la puesta en escenario del tratamiento de las NEE solo ocurre a partir de estos dos hechos y en el marco de una nueva política nacional que visibiliza a las personas con discapacidad y procura una inclusión educativa que va más allá de ella. Es, sin embargo, necesario mirar la vivencia de 
un estudiante con NEE (asociadas a discapacidad visual) bajo el nuevo marco jurídico. Este artículo da cuenta del estudio de su caso, su desarrollo estudiantil amparado por este marco jurídico pero con el carácter especial de haberlo realizado en un centro educativo regular y de carácter privado (no público). Su visión es contrastada con la de sus docentes y mirada a partir de lo que promueve la Constitución, las leyes y las normativas. Se extraen conclusiones acerca de las conquistas que este marco jurídico ha dado a los estudiantes con NEE y se establecen también los vacíos que se requieren llenar para conseguir una inclusión educativa integral y, por ende, un oportuno tratamiento de las NEE.

\section{ABSTRACT}

The adoption of the Constitution of the Republic of Ecuador (2008) and the enactment of the Intercultural Education Organic Law (2008) marked a milestone in the way of managing Special Education Needs in Ecuador. It is undeniable that the way of managing SEN has only taken importance with these two events and in a framework of a new national policy that makes people with disabilities visible and ensures a new educational inclusion beyond it. It is, however, necessary to take a look at a student with SEN's (Associate with visual disability) experience under the new legal framework. This article renders account of his case study, his educational development under this new legal framework but with the special characteristic of having studied in a regular educational center and private (not public). His vision is contrasted with the one from his teachers and observed from what the Constitution, laws and norms promote. Some conclusions are drawn about the benefits this legal framework has given to students with SEN and also establish the gaps needed to fill to obtain an integral educational inclusion and, therefore, a timely management of SEN.

\section{INTRODUCCIÓN}

En la República del Ecuador, el tratamiento de las Necesidad Educativas Especiales tiene un antes y un después con la aprobación de la Constitución de 2008. Este documento y las leyes y normas que de él se desprenden, estable- 
cieron un nuevo ámbito en la vida educativa del país. Iba esto de la mano del revalorizado tratamiento de las discapacidades. En el 2013, la Agenda Nacional para la Igualdad en Discapacidades 2013-2017 ya reconocía, luego de un estudio nacional, algunas deficiencias, en materia educativa, del tratamiento de las discapacidades —un área significativa de las NEE-, de las cuales, entre otras, podemos citar los presupuestos gubernamentales limitados para atender a las PCD, la carencia de una unidad ministerial educativa encargada de la educación inclusiva y especial, falta de indicadores del estado actual de la educación inclusiva y especial y un insuficiente control de la calidad en la educación inclusiva y especial (CONADIS, 2013, págs. 79-80). Es pues claro que, por un lado, contamos ya con un cuerpo legal que ampara a las personas con discapacidades y, más allá de ella, promueve en el ámbito educativo el tratamiento de las Necesidades Educativas Especiales (NEE), y, por otro, un estado de la situación que debe aún ser trabajado a profundidad a fin de conseguir la inclusión plena. Ante este diagnóstico, nos planteamos investigar cuáles eran las principales carencias y dificultades que tuvo que enfrentar un estudiante de último año de bachillerato con NEE (en este caso, asociadas a una discapacidad visual), cuál fue el rol de los do- centes en su proceso de aprendizaje. Escogimos así un estudiante de 18 años de edad que cursa el tercer año de Bachillerato General Unificado en una institución educativa de tipo particular. Por su voz y las de sus docentes buscamos conocer el rol de la institución educativa en el trabajo de la inclusión educativa, el apoyo familiar y de sus compañeros. Todo ello fue analizado a la luz de lo que promueve y exige el marco jurídico ecuatoriano actual para vislumbrar las nuevas dificultades de los estudiantes con NEE y el alcance de las nuevas leyes y su impacto en la inclusión educativa.

\section{Las Necesidades Educativas Especiales}

La aparición del Informe de Warnock (Committee of Enquiry into the Education of Handicapped Children and Young People, 1978) marcó un giro conceptual en la Educación al plantear conceptos fundamentales como el de "necesidades educativas" y el de que estas son comunes a todos los niños. Desde entonces hablamos de Necesidades Educativas Especiales (NEE) en detrimento de otras denominaciones y concepciones reductivas: se educa para satisfacer esas necesidades y no para resolver problemas educativos.

Las NEE comprenden las exigencias no contempladas en el curso regular educativo y de carácter específico para 
dar soporte a los estudiantes de modo que puedan realizar sin limitaciones su proceso de aprendizaje (Bermeosolo Bertrán, 2010, pág. 164). Es una concepción totalizadoramente satisfactoria del área que nos ocupa. Es decir, abarca desde las discapacidades hasta necesidades temporales (lesiones físicas curables pero que exigen adecuaciones educativas).

En el Ecuador, la inclusión de las NEE en el marco legal empieza a partir de 2006 con la propuesta y ejecución del Plan Decenal de Educación del Ecuador 2006-2015 por parte del Consejo Nacional de Educación y el Ministerio de Educación pero, sobre todo, con la aprobación de la Constitución de la República del Ecuador en 2008. Este nuevo marco constitutivo establece -en su artículo 35- la prioridad de atención para las personas con discapacidad (entre otros grupos) (Asamblea Constituyente del Ecuador, 2008). Es mandatario y concerniente al ámbito educativo lo señalado en el literal 3) del artículo 36: "Atención preferente para la plena integración social de quienes tengan discapacidad. El Estado garantizará su incorporación en el sistema de educación regular y en la sociedad". Pero, además, la misma Constitución establece en el artículo 47 que se garantizará a las personas con discapacidad "su educación dentro de la educación regular" (Asamblea Constituyente del Ecuador, 2008). Este apartado inaugura el proceso de inclusión de las personas con discapacidad en la educación regular y cuyo tránsito y resultado analizamos en el estudio de caso que se presenta en este escrito. En el mismo artículo se especifica que los planteles educativos deberán brindar un trato diferenciado. Además, se exige que dichas instituciones acaten las normas de accesibilidad establecidas paras las personas con discapacidad. Por último, los centros escolares deben establecer una oferta de becas acorde con las condiciones económicas de las personas de este grupo. Este marco legal —así establecido desde el espacio rector de la vida de una nación llamado constitución- deja en claro la forma en que a partir de entonces las personas con discapacidad acceden a la educación regular — más allá de establecerse también políticas para la educación especializada-y los términos últimos que deben cumplir las instituciones educativas a fin de garantizar ese acceso educativo.

No se puede pasar por alto tampoco la precisión que establece esta misma Constitución en el caso de que no se cumplieran las políticas establecidas para la inclusión de las personas con discapacidad o no se velara por sus derechos: "La ley sancionará el abandono de estas personas, y los actos que incurran en cualquier forma de abuso, trato inhumano o degradante y discriminación 
por razón de la discapacidad" (Asamblea Constituyente del Ecuador, 2008).

El concepto de Necesidades Educativas Especiales es definido, en cambio, por el Reglamento General a la Ley Orgánica de Educación Intercultural del Ecuador: "Son estudiantes con necesidades educativas especiales aquellos que requieren apoyo o adaptaciones temporales o permanentes que les permitan acceder a un servicio de calidad de acuerdo a su condición. Estos apoyos y adaptaciones pueden ser de aprendizaje, de accesibilidad o de comunicación" (Asamblea Nacional del Ecuador,
2012, pág. 118). Esta concepción rebasa, como hemos dicho, el marco de la discapacidad y abarca de forma totalizadora al conjunto de estudiantes en sus diversos requerimientos de desarrollo y formación.

Este reglamento establece además la clasificación de las NEE: necesidades educativas especiales no asociadas a la discapacidad y necesidades educativas especiales asociadas a la discapacidad. Presentamos un cuadro con la clasificación establecida por el reglamento General a la Ley Orgánica de Educación Intercultural:

\begin{tabular}{|l|l|l|l|l|l|}
\hline \multicolumn{3}{|c|}{$\begin{array}{l}\text { NECESIDADES EDUCATIVAS ESPECIALES } \\
\text { NO ASOCIADAS A LA DISCAPACIDAD }\end{array}$} & \multicolumn{2}{|c|}{$\begin{array}{l}\text { NECESIDADES EDUCATIVAS ESPECIALES } \\
\text { ASOCIADAS A LA DISCAPACIDAD }\end{array}$} \\
\hline $\begin{array}{l}\text { Dificultades } \\
\text { específicas de } \\
\text { aprendizaje }\end{array}$ & $\begin{array}{l}\text { Situaciones de } \\
\text { vulnerabilidad }\end{array}$ & Dotación superior & $\begin{array}{l}\text { Discapacidad } \\
\text { intelectual, } \\
\text { física-motriz, } \\
\text { auditiva, visual 0 } \\
\text { mental }\end{array}$ & $\begin{array}{l}\text { Multidiscapaci- } \\
\text { dades }\end{array}$ & $\begin{array}{l}\text { Trastornos } \\
\text { generalizados } \\
\text { del desarrollo } \\
\text { (autismo, síndro- } \\
\text { me de Asperger, } \\
\text { síndrome de Rett, } \\
\text { entre otros). }\end{array}$ \\
\hline $\begin{array}{l}\text { Dislexia, discal- } \\
\text { culia, disgrafía, } \\
\text { disortografía, } \\
\text { disfasia, trastor- } \\
\text { nos por déficit } \\
\text { de atención e } \\
\text { hiperactividad, } \\
\text { trastornos del } \\
\text { comportamiento, } \\
\text { entre otros. }\end{array}$ & $\begin{array}{l}\text { Enfermedades } \\
\text { catastróficas, mo- } \\
\text { vilidad humana, } \\
\text { menores infrac- } \\
\text { tores, víctimas } \\
\text { de violencia, } \\
\text { adicciones y otras } \\
\text { situaciones excep- } \\
\text { cionales previstas } \\
\text { en el presente } \\
\text { reglamento. }\end{array}$ & $\begin{array}{l}\text { Altas capacidades } \\
\text { intelectuales. }\end{array}$ & & & \\
& & & & & \\
& & & & \\
\end{tabular}

Elaboración: autores 
La inclusión educativa de los estudiantes con necesidades educativas especiales está amparada además por el artículo 229 de este reglamento, que señala la posibilidad de que estos estudiantes pueden ser atendidos en un establecimiento educativo especializado o en uno de educación escolarizada. Este mismo apartado señala la disposición de "equipos de profesionales especializados en la detección de necesidades educativas especiales, quienes deben definir cuál es la modalidad más adecuada para cada estudiante y deben brindarles atención complementaria, con servicio fijo itinerante". Como veremos más adelante, en el caso seleccionado para este artículo, no ha existido esa atención complementaria ni ese servicio fijo itinerante de apoyo a la inclusión educativa de este estudiante.

Las NEE exigen que las instituciones educativas y los docentes adecuen el proceso de aprendizaje a partir de las particularidades del estudiante. Como sostiene la Declaración de Salamanca de Principios, Política y Práctica para las Necesidades Educativas Especiales, "cada niño tiene características, intereses, capacidades y necesidades de aprendizaje que le son propios" y "los sistemas educativos deben ser diseñados y los programas aplicados de modo que tengan en cuenta toda la gama de esas diferentes características y necesidades" (ONU,
1994, págs. 8-9). De este modo, las adaptaciones curriculares no se dan de forma generalizada sino que se trabajan según el contexto particular de cada estudiante con NEE. Son estas las que marcan el rumbo de la inclusión y las instituciones educativas están conminadas a determinar qué es lo que necesita cada estudiante, y construir, liderando a su comunidad educativa, el espacio y el proceso educativo que las satisfaga.

Al hablar de adaptaciones curriculares nos referimos a "toda adaptación individualizada que se realiza para un estudiante al que el currículo ordinario no da respuesta a sus necesidades, por lo que no puede acceder a él de la misma forma que sus compañeros y compañeras. Por tanto, deberá tomarse como base la Programación de Aula concreta en la que dicho estudiante se encuentre escolarizado o escolarizada" (Gento Palacios \& Lakhdar, 2010, pág. 89). De nuevo, el concepto nos remite al principio de trabajar las NEE a partir del estudiante: las adaptaciones curriculares son en función de él, y en ningún caso las NEE son iguales de estudiante a estudiante en virtud de que hablamos de dos personas distintas.

\section{Discapacidad visual}

La discapacidad visual y su grado, para los consecuentes efectos legales, es determinada en el Ecuador por el Minis- 
terio de Salud Pública. Para los fines consiguientes, citamos las siguientes definiciones de ceguera e incapacidad parcial (Martino \& Barrera, 2003):

Ceguera: agudeza visual de 20/200 o menos, en el mejor ojo con corrección, o un campo visual que no alcanza un ángulo superior a los $20^{\circ}$. Incapacidad visual parcial: agudeza visual por encima de 20/200, pero inferior a 20/70 en su mejor ojo con corrección (pág. 73).

El entorno educativo debe tomar en cuenta las NEE de los estudiantes con discapacidad visual a fin de ser efectivamente inclusiva. Otros aspectos que los docentes deben considerar en el proceso de aprendizaje están los señalados por Pierangelo, R. y Jaboby, R. (1998), de los cuales presentamos aquí un resumen pertinente (Pierangelo \& Jacoby, 1998, pág. 144):

1. La habilidad de modelar su comportamiento está limitada a causa del impedimento de poder ver los gestos faciales de las personas de su entorno (profesores, compañeros, amigos y padres). Esta circunstancia afecta particularmente su grado de interacción social.

2. Debe considerarse que un alto porcentaje de personas invidentes pre- senta discapacidades adicionales asociadas, lo cual exige otras adaptaciones curriculares y propuestas de satisfacción de sus NEE.

3. El espacio físico de las instituciones educativas debe contemplar las particulares NEE de cada estudiante con discapacidad.

La atención de las NEE de los estudiantes con discapacidad visual demanda la asunción, por parte de los docentes y la institución educativa en general, de que su desarrollo requiere una alta estimulación de los otros sentidos (oído, gusto, tacto, olfato) si es que no existe otra discapacidad asociada. Un trabajo enfocado bajo esta realidad evitará, por ejemplo, el aparecimiento de actitudes de dependencia junto con un decrecimiento de la seguridad en su capacidad de desempeño (González \& Zardini, 2007, pág. 74).

\section{TICs, educación y discapacidad visual}

Las TICs han contribuido enormemente a facilitar el aprendizaje de las personas con discapacidad. En cuanto a los estudiantes con NEE relacionadas a la discapacidad visual, las TICs han ayudado, entre otras cosas, a eliminar el soporte mediador de la persona entre ellos y el conocimiento. Gracias a la tecnología, los estudiantes con discapa- 
cidad visual pueden acceder de forma personal, inmediata y de primera mano a la información que necesitan manejar. Por otro lado, la tecnología y los múltiples recursos que de ella se han derivado para ayudar en el aprendizaje de estos grupos, va volviendo irrelevante el aprendizaje del sistema de lectura y escritura Braille. Este hecho se ha evidenciado en el estudio de caso que se presenta más adelante.

Los principales recursos de las TICs (García Villalobos, 2011, págs. 33-34) para los estudiantes con discapacidad son:

a. Ampliadores de pantalla: modifican los atributos de las pantallas con capacidad de hasta 16 aumentos.

b. Revisores de pantalla: programas que transforman la información de la pantalla en una síntesis de voz o una línea Braille. Para el sistema operativo Windows, el más utilizado es el programa JAWS.

Algunos recursos que ofrecen las TICs no están diseñados expresamente para personas con discapacidad visual, pero son útiles para facilitar el aprendizaje. Entre estos tenemos la interfaz vocal de entrada de datos que permite manejar un dispositivo (PC, Tablet o teléfono celular) e incluso dictar texto. El escáner combinado con un software OCR permite reconocer con alta fidelidad textos escritos y convertirlos a formato digital que luego puede ser reproducido por el lector de pantalla (Gento Palacios, 2010, pág. 66). Esta herramienta sirve tanto a los estudiantes con discapacidad como a los docentes que pueden con ella recrear y adaptar recursos escritos impresos a formato digital y ofrecerlos a sus alumnos con discapacidad visual.

En todos estos casos, para el uso de las TICs para la accesibilidad, las instituciones educativas deben tener una política clara respecto al uso de la tecnología por parte de los estudiantes en el aula. En el contexto ecuatoriano, se puede notar en diversos contextos educativos la restricción que pueden tener los alumnos para usar computadoras portátiles, celulares o tabletas dentro de la clase. Un estudiante con discapacidad visual encuentra enormes ventajas para su aprendizaje al apoyarse en las TICs; es, por tanto, necesario que se facilite el uso de su ordenador personal en todo momento y que los docentes conozcan los recursos tecnológicos que usa este estudiante, a los cuales los recursos didácticos deben adaptarse, así como también las otras TICs de las que puedan valerse los docentes para satisfacer las NEE. 


\section{MATERIALES Y MÉTODOS}

En este estudio de caso utilizamos el método de la entrevista para recabar toda la información pertinente al estudiante seleccionado. Las preguntas que guiaron la entrevista exploraron las dificultades que encontró el estudiante de control durante su carrera estudiantil en el proceso de aprendizaje, sus fortalezas, los recursos disponibles y empelados, así como la participación de la comunidad educativa en su formación: su propia familia, sus compañeros, los docentes y las autoridades.
Del estamento docente se obtuvo la información con la aplicación de una encuesta de nueve preguntas semicerradas. Con el estudiante se elaboró una lista de los docentes que habían participado en su formación y se solicitó la autorización a los directivos de la institución educativa para aplicar la encuesta. De un total de 30 docentes a los que se les solicitó llenar la encuesta, participaron 10.

Las encuestas aplicadas a los docentes tuvieron carácter anónimo.

\section{RESULTADOS}

\section{DATOS PERSONALES DE LOS DOCENTES ENCUESTADOS}

EDAD DE LOS DOCENTES ENCUESTADOS

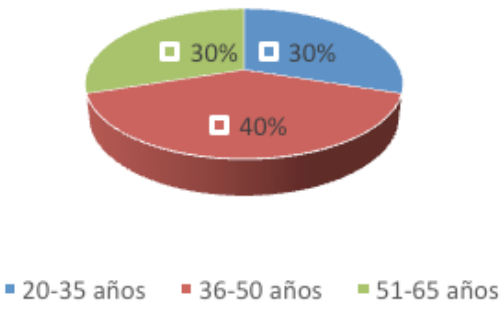




\section{TIEMPO DE EJERCICIO DOCENTE}

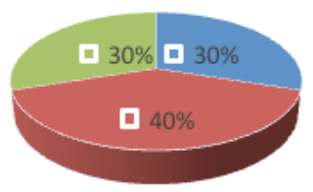

- 0 - 10 años = 11 - 20 años $\quad 21$ - 30 años

TíTULO ACADÉMICO

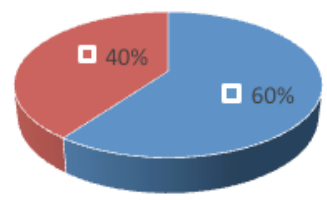

- Título de 3er nivel = Título de 4to nivel

\section{RESULTADOS DE LAS PREGUNTAS PLANTEADAS A LOS DOCENTES ENCUESTADOS}

\section{Pregunta 01}

¿Está usted de acuerdo con el apartado del Reglamento de la Ley Orgánica de Educación Intercultural que promueve la inclusión de personas con discapacidad en las instituciones de educación escolarizada ordinaria?

Acuerdo con la LOEI

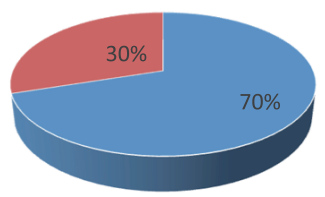

- Sí " No 


\section{Razones para el sí}

- Derecho a la educación e inclusión

- Las personas con discapacidad tienen los mismos derechos y las mismas capacidades.

- Búsqueda de inclusión social

- Sentido de justicia

\section{Razones para el no}

- No hay capacitación en la universidad para educar a PCD.

- Inclusión es discriminatoria, los estudiantes ciegos deben estar con estudiantes ciegos.

- Permanencia en centros especializados para ciegos.

\section{Pregunta 02}

¿Cómo valora su formación en el tema de Inclusión Educativa con miras a dar cumplimiento al Reglamento de la Ley Orgánica de Educación Intercultural en lo referente a este tema?

Valoración de la formación docente

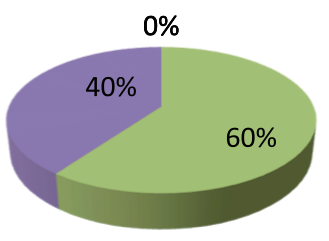

Excelente

Muy bueno

Bueno

Regular

Razones por las que considera que su formación en el tema de Inclusión Educativa con miras a dar cumplimiento al Reglamento de la Ley Orgánica de Educación Intercultural en lo referente a este tema es buena o regular:

- No hay formación universitaria, ninguna asignatura que enseñe para educar a PCD.
- Desconocimiento sobre NEE y su forma de tratarlas.

- No existe capacitación adecuada para las NEE.

- El Ministerio debería capacitar si quiere el cumplimiento de esta ley.

- Escasa experiencia en la docencia, poca capacitación.

- Autopreparación para solventar la falta de capacitación. 


\section{Pregunta 03}

En general, ¿cómo valora usted los procesos de Inclusión Educativa llevados a cabo en la institución educativa donde labora?

Valoración de los procesos institucionales de inclusión

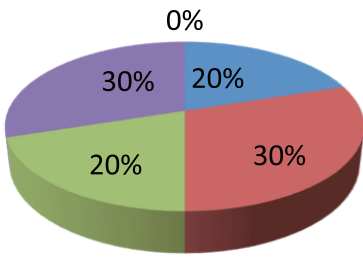

Excelente

Muy bueno

Bueno

- Regular

Malo

Razones por las que valora positi- educativa donde labora: vamente los procesos de Inclusión Educativa llevados a cabo en la institución - No se aplican normativas de entidaeducativa donde labora: des superiores de forma clara.

- No estamos capacitados.

- Los docentes trabajan en función de . Falta infraestructura. las NEE.

- Falta de capacitación

- Hay que cumplir para servir a los es- DECE (Departamento de Consejería tudiantes Estudiantil) no se involucra ni brinda apoyo.

Razones por las que valora nega- • 6 años de inclusión con el estudiantivamente los procesos de Inclusión Educativa llevados a cabo en la institución te de control y aún estamos aprendiendo.

\section{Pregunta 4}

¿En qué medida se ha sentido respaldado/a en su tarea de lograr un verdadero proceso de inclusión educativa por parte de los miembros de la Comunidad Educativa (Autoridades, DECE, compañeros docentes de otras áreas, padres de familias, estudiantes). 


\section{Respaldo al proceso de inclusión}

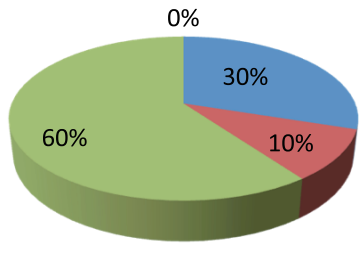

Razones para una valoración po-

\section{Mucho \\ - Suficiente \\ Poco \\ - Nada} sitiva:

Razones para una valoración negativa:

- DECE acompaña y hace seguimien- - Desconocimiento de instructivos. to.

- DECE lleva un control detallado de los estudiantes, se preocupan por el trabajo dentro de fuera del aula.

- Respaldo total por la Filosofía de la institución.
- Necesidad de trabajo multidisciplinario.

- No existe espacio ni tiempo para realizar una inclusión verdadera.

- Material didáctico insuficiente.

- Al inicio DECE dio pautas que no fueron suficientes.

\section{Pregunta 5}

De los siguientes temas, ¿cuáles considera que son importantes establecer para su capacitación docente en temas de inclusión?

\section{Temas de capacitación}

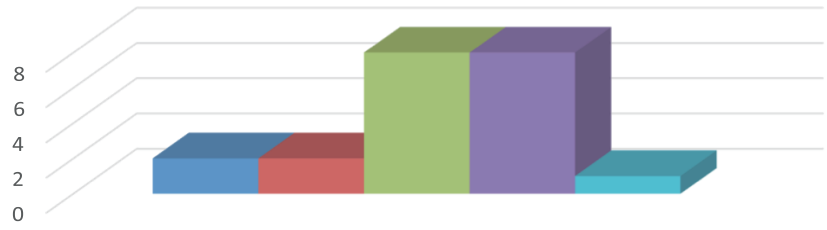

Pregunta 5

- Discapacidad

- Inclusión

- Adaptaciones curriculares

- Tecnologías informáticas para inclusión y discapacidad

- Otros (Estrategias metodológicas específicas para cada tema) 


\section{Pregunta 6}

¿Cuáles fueron sus mayores dificultades en su desempeño docente con respecto al estudiante de control?

\section{Dificultades de desempeño docente}

10

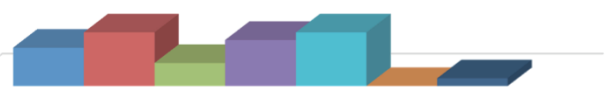

Pregunta 6

- Falta de capacitación en el tema de discapacidad visual

- Desconocimiento del braille

- Desconocimiento de lectores de pantallas adaptados para personas con discapacidad visual.

- Falta de capacitación y/o desconocimiento en adaptaciones curriculares

- Dificultad en la adaptación de los recursos didácticos

- Limitación física en la movilidad del estudiante

\section{Pregunta 7}

¿Qué actitudes evidenció en los compañeros del estudiante de control durante su proceso de aprendizaje?

\section{Actitudes de los compañeros}

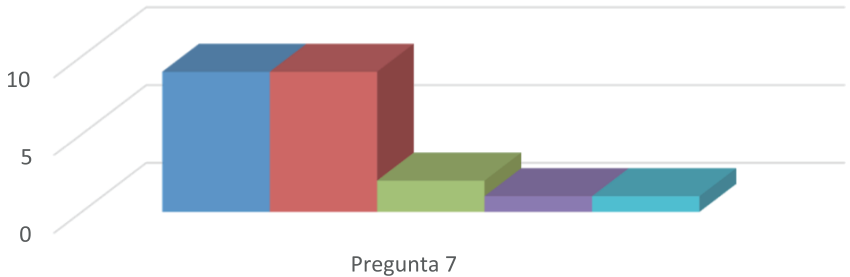

- Apertura para la integración en trabajos grupales

- Solidaridad

- Frustración (Por no poder ayudarle)

- Temor (Por no saber cómo ayudarle)

Otras: Compromiso, prestos ayudar en las necesidades de Esteban. 


\section{Pregunta 8}

¿Cómo considera usted los recursos que utilizó el estudiante de control para su aprendizaje (por ejemplo: computadora, teléfono celular, otros)?

Valoración de los recursos de aprendizaje utilizados por el estudiante

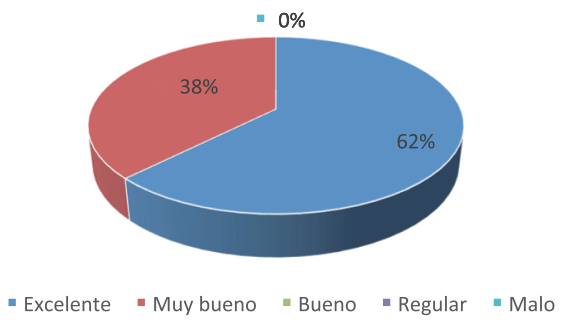

\section{Razones:}

"eso le ayudado a defenderse".

- Recursos y capacidad tecnológicas - Inteligente, domina la tecnología. excelentes.

- Información digitalizada.

- Manejo muy bueno de la tecnología, - Tecnología facilita el conocimiento.

- Buen manejo, el estudiante de control ayuda a sus compañeros.

\section{Pregunta 9}

Valore el apoyo de la familia del estudiante de control en el proceso de inclusión.

\section{Valoración del apoyo familiar}

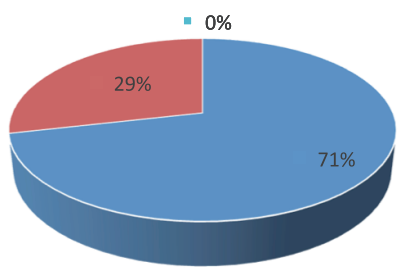

- Excelente " Muybueno "Bueno - Regular "Malo 


\section{Razones:}

- Familia gestora de la educación.

- Familia proporciona lo necesario.

- Pendientes del desarrollo académico y de su formación.
- Siempre involucrados.

- Apoyo constante.

- Pendientes todo el tiempo.

- Se destaca la predisposición de estudiante para trabajar y aprender.

\section{DISCUSIÓN}

Las razones que expresan los docentes para justificar su desacuerdo con el apartado del Reglamento de la LOEI que promueve la inclusión de personas con discapacidad en las instituciones de educación escolarizada ordinaria, se relacionan con su falta de capacitación sobre estos mismos temas desde las épocas universitarias. Esa relación se evidencia también en la postura de considerar que las personas con discapacidad deben estudiar en centros especializados en su discapacidad.

Sin embargo, destaca la circunstancia de que la mayoría de docentes sostenga que las personas con discapacidad tienen los mismos derechos que aquellos que no tienen discapacidad y pueden y deben acceder a los mismos servicios de la educación regular.

La postura del estudiante de control al respecto es categórica: su acceso a la educación regular es posible gracias, precisamente, a la LOEI. Puesto que en su entorno familiar hay personas también con discapacidad visual mucho mayores que él, tiene conocimiento de que el acceso a la educación regular antes de la publicación de esta ley era prácticamente nulo y dejaba a las personas con discapacidad en una posición de sumisión respecto al poder educativo (público particular) que podía decidir sin ninguna presión legal si las admitía o no.

De la misma forma, el estudiante de control considera que, al amparo de esta ley, exigir mayores beneficios para su inclusión es posible por el carácter privado de la institución educativa en la que se encuentra escolarizado. Su conocimiento de las vivencias de otros estudiantes con discapacidad visual que cursan estudios en centros escolares públicos le permite asegurar que el conseguir ventajas puede ser más difícil.

Por otra parte, las razones expresadas en la autoevaluación que realiza este grupo docente de su formación en el tema de inclusión educativa hacen referencia a sus orígenes universitarios. Así, 
no existe formación profesional superior que les haga sentirse competentes en el tema de la inclusión educativa, ni la capacitación permanente durante el ejercicio del magisterio. Esto podría reflejarse en los números que propone el estudiante de control en cuanto al porcentaje de docentes que realizaron adaptaciones. Así, en cuanto a la adaptación de método, el estudiante de control considera que el $90 \%$ de sus docentes lo realizó. Por el contrario, en cuanto a la adaptación de los instrumentos de evaluación — un área en la que probablemente se requiera mayor conocimiento que el aportado por la formación docente de pregrado y posgrado-, el estudiante de control considera que el $60 \%$ de los docentes pudo realizarla. Parecería un porcentaje alto si no se considera que, de ser las cifras así, el estudiante de control tuvo dificultades de accesibilidad en 4 de cada diez instrumentos de evaluación que se le aplicaron.

Tampoco es insignificante la relación entre el periodo de trabajo de los docentes en esta institución educativa y su valoración de los procesos de inclusión educativa en dicho centro (pregunta 3) así como en el sentimiento de respaldo a su tarea otorgado por los miembros de esa comunidad educativa (pregunta 4). Es decir, son los docentes con menor permanencia en esta institución los que mejor puntúan estos aspectos. Mientras que los docentes que valoran con menor puntuación los procesos de inclusión apelan de nuevo a la capacitación - como un factor no facilitado por el centro educativo-, a la infraestructura, a una normativa poco clara o a estamentos competentes que no fortalecen estos procesos (el DECE, por ejemplo).

Lo mismo ocurre en el ítem 4. Los docentes que valoran negativamente el apoyo de la Comunidad Educativa a estos procesos, señalan razones que se refieren al ámbito de los recursos, estamentos (DECE) y, significativamente, a la carencia de un trabajo colectivo (multidisciplinar).

Para el estudiante de control, son sus compañeros los que mejor apoyan el proceso de inclusión, por encima de la institución y de los docentes. Con las limitaciones e intereses señalados, los docentes en mayor o menor medida buscaron propender, cada uno en una medida diferente, la inclusión educativa del estudiante. Pero allí, donde la labor docente no alcanzaba o era nula, y donde la institución educativa no brindaba soporte, los compañeros solventaban esas deficiencias por el vínculo afectivo establecido en la convivencia y no por una motivación institucional.

Si tomamos en conjunto los resultados de la pregunta 5 como los de la 6, veremos que los temas que los do- 
centes consideran más importantes para su capacitación tienen relación con las áreas en las que su desempeño encontró mayores dificultades con respecto al estudiante de control: las adaptaciones curriculares y la tecnología como herramienta para trabajar la inclusión.

Al respecto, el estudiante precisa un aspecto evidente del ámbito legal aplicado a la praxis educativa: las regulaciones establecen la obligatoriedad de la inclusión educativa pero no establecen la forma en que esta se realizará. De lo que resulta que los docentes - por desconocimiento o falta de recursos - encuentran como mayor óbice el área de la adaptación de los recursos y el currículo, terreno en el que el estudiante también se reconoce limitado y, por tanto, impelido a exigir soluciones docentes.

Resulta paradójico que el $70 \%$ de los docentes considere que la mayor dificultad en su desempeño respecto del estudiante de control es el "Desconocimiento del Braille" puesto que él, por el contrario, asegura que a partir de $6^{\circ}$ año de EGB dejó de usar ese sistema de lecto-escritura porque no alcanzaba a tomar los dictados de los docentes y pasó a apoyarse en una grabadora. La satisfacción de las necesidades del estudiante con discapacidad, en este caso, se enfrentan con el hecho totalmente opuesto: un desconocimiento por parte de los docentes de lo que realmente necesita el estudiante.

En cuanto al aspecto de inclusión social, los resultados de la pregunta 7 de la encuesta aplicada a los docentes concuerda con lo expresado por el estudiante en su entrevista personal: fue plena y satisfactoria en virtud del apoyo que recibió de sus compañeros. Si la evolución de la tecnología brindó importantes herramientas que podían mejorar el desempeño de los estudiantes con discapacidad, el uso que de ellas realizaron sus compañeros terminaron tornando altamente satisfactoria la inmersión del estudiante de control en el entorno escolar. Sus compañeros se prestaron para, por ejemplo, grabar notas de voz con las que le informaban de tareas y lecturas que no habían sido digitalizadas haciendo de ese modo, una vez más, accesible el conocimiento.

Los recursos usados por el estudiante de control son principalmente de tipo tecnológico y los docentes brindan una evaluación muy alta a su manejo: mayoritariamente excelente $y$ también muy bueno. En la entrevista, el estudiante consolida esta perspectiva de los docentes: su manejo de los recursos, principalmente tecnológicos, es amplia y eficiente. Pero ello responde únicamente a una iniciativa particular de él mismo en su afán de acceder a la educación y 
participar en ella (y en la vida en general) en el mismo grado en que lo hacen otras personas sin discapacidad. Una acertada iniciativa gubernamental le concedió un ordenador portátil con un software libre. Sin embargo, la iniciativa se vio truncada en esa entrega. No existió capacitación ni actualización por parte de ningún otro organismo público. Mucho menos la institución educativa ha facilitado recursos tecnológicos ni de ningún otro tipo que pudieran responder a una política clara y efectiva del centro escolar por fomentar la inclusión educativa. Todo el conocimiento que maneja el estudiante de control ha sido obtenido por iniciativa suya en fuentes contactadas por él o por su entorno familiar. Un ejemplo: el software que se ofreció instalado en el ordenador portátil no fue útil o suficientemente útil de modo que el estudiante consiguió el programa más usado por personas con discapacidad visual en ordenadores, el JAWS. Este hecho se enfrenta a lo establecido, como hemos visto, en el artículo 229 del Reglamento General de la Ley Orgánica de Educación Intercultural, que señala la disposición de equipos profesionales especializados "en la detección de necesidades educativas especiales, quienes deben definir cuál es la modalidad más adecuada para cada estudiante y deben brindarles atención complementaria, con servicio fijo e itinerante". A pesar de ello, no ha existido un seguimiento educativo al estudiante de control, un apoyo en la capacitación para el uso de los recursos tecnológicos más modernos y útiles al servicio de la accesibilidad para la discapacidad visual.

El apoyo de la familia del estudiante de control es valorado por los docentes también en un grado alto (mayoritariamente "Excelente"y"Muy bueno", ningún otro valor es escogido). Esta característica es ratificada por el estudiante: entre una serie de elementos, escoge como punto más trascendente en su proceso de inclusión el apoyo familiar. En segundo lugar, destaca su propia actitud. De ahí que haya sido fundamental una cualidad familiar crucial en este punto: propender siempre a establecer y expandir las redes de contacto social del estudiante de control. 


\section{CONCLUSIONES}

1. Los docentes que se oponen a la inclusión de las personas con discapacidad en la educación regular argumentan su postura a partir de sus carencias de capacitación en el tema.

2. El pensum universitario de los docentes no contemplaba ningún tema o asignatura que brindara un conocimiento mínimo de las NEE.

3. El apoyo familiar resulta necesario en extremo a fin de que la inclusión educativa (y social, en general) pueda aumentar su factibilidad y consolide un entramado de relaciones que faciliten el desarrollo educativo del estudiante con discapacidad.

4. No existe un apoyo permanente del equipo de profesionales especializados que deben brindar atención complementaria en servicio fijo e itinerante como lo establece el artículo 229 del Reglamento General a la Ley Orgánica de Educación Intercultural.
5. No hay evidencia de una aplicación consistente de la política de inclusión educativa establecida por la institución educativa.

6. Se carece de capacitación específica brindada por la institución educativa a los docentes para contribuir en la inclusión educativa.

7. Se carece de evidencia de un trabajo de sensibilización y capacitación de los estudiantes sin discapacidad a fin de que puedan promover y contribuir en la inclusión de sus compañeros con discapacidad, sino que más bien ésta nace del contacto y el trabajo por propia iniciativa de la persona con discapacidad.

8. La implementación tecnológica de la institución educativa para la inclusión educativa no es suficiente y en muchos casos se resuelve por la iniciativa de los docentes, los estudiantes y la misma persona con discapacidad. 


\section{RECOMENDACIONES}

1. Determinar la efectiva creación e implementación de una política educativa de inclusión propia de cada institución educativa.

2. Fortalecer, por parte de la Autoridad Educativa Nacional, sistemas de seguimiento y evaluación de las políticas educativas de inclusión de las instituciones educativas particulares.

3. Mejorar el servicio de asistencia y seguimiento por parte de los equipos profesionales de los estudiantes con necesidades educativas especiales asociadas a discapacidad.

4. Levantar estadísticas nacionales del acceso a la educación especializada y regular de las personas con discapacidad y de sus resultados.
5. Diseñar y ejecutar planes de capacitación nacionales para docentes de establecimientos educativos privados en materia de inclusión educativa.

6. Incentivar a través de políticas constantes que contemplen estímulos significativos a las instituciones educativas particulares por el acceso que brinden a estudiantes con discapacidad y sus logros en el tratamiento de las NEE.

7. Diseñar y ejecutar políticas de sensibilización y capacitación de todos los estamentos de la comunidad educativa por parte de la institución particular y divulgar y compartir su experiencia en todos los espacios de intercambio pedagógico con otros centros escolares. 


\section{REFERENCIAS}

Asamblea Constituyente del Ecuador. (2008). Constitución de la República del Ecuador. Quito: Corporación de Estudios y Publicaciones.

Asamblea Nacional del Ecuador. (2012). Reglamento General a la Ley Orgánica de Educación Intercultural. Quito: Corporación de Estudios y Publicaciones.

Bermeosolo Bertrán, J. (2010). Psicopedagogía de la diversidad en el aula. México: Alfaomega .

Committee of Enquiry into the Education of Handicapped Children and Young People. (1978). Report of Committee of Enquiry into the Education of Handicapped Children and Young People. Obtenido de http://www.educationengland. org.uk/documents/warnock/ warnock1978.html\#00

CONADIS. (2013). Agenda Nacional para la Igualdad en Discapacidades 2013-2017. http://www.consejodiscapacidades.gob.ec/.

García Villalobos, J. (2011). Acceso a las TIC para alumnos con discapacidad visual. En M. d. España, Acce- sibilidad, TIC y Educación. España: Secretaría General Técnica.

Gento Palacios, S. (2010). Materiales convencionales y tecnológicos para el tratamiento educativo de la diversidad. Madrid: UNED.

Gento Palacios, S., \& Lakhdar, S. M. (2010). Diseño y ejecución de planes, proyectos y adaptaciones curriculares para el tratamiento educativo de la diversidad. Madrid: UNED.

González, M., \& Zardini, M. (2007). Discapacidad visual. En R. Martino, \& L. Barrera, El niño discapacitado (págs. 73-77). Argentina: Nobuko.

Martino, R. H., \& Barrera, L. (2003). El niño discapacitado. Argentina: Nobuko.

ONU. (1994). Declaración de Salamanca y Marco de Acción para las Necesidades Educativas Especiales. Salamanca: Unesco.

Pierangelo, R., \& Jacoby, R. (1998). Guía de Educación Especial para niños discapacitados. México: Prentice Hall. 